\title{
LIÇÕES APRENDIDAS SOBRE INFORMAÇÃO, EDUCAÇÃO E COMUNICAÇÃO EM SAÚDE PARA A PREVENÇÃO DA CHIKUNGUNYA EM PAÍSES COM ÁREAS DE RISCO: UMA SCOPING REVIEW
}

Introdução: Em resposta à emergência e aos atuais surtos de CHIK e mudanças em sua epidemiologia no Brasil, essa situação nos indaga: quais as lições aprendidas sobre práticas e programas de Informação, Educação e Comunicação (IEC) para a prevenção da doença na população de países com áreas de risco?

Objetivo: O objetivo desta Scoping review foi identificar e caracterizar a literatura disponível sobre ações de prevenção relacionadas à informação, educação e comunicação em saúde (IEC) para Chikungunya entre países com áreas de risco no mundo.

Métodos: Realizamos uma Scoping Review usando as orientações de Arksey e O’Malley e o Manual do Instituto Joanna Briggs. Um protocolo detalhado foi preparado e revisado pela equipe de pesquisa, que incluiu epidemiologista, sanitarista, comunicóloga em saúde e bibliotecários especializados em gerenciamento de dados. As diretrizes para Scoping Reviews do PRISMA-ScR foram seguidas para orientar o desenvolvimento deste estudo. Oito bases de dados foram pesquisadas. Estudos em inglês, espanhol e português foram incluídos. Nenhum limite de datas foi definido. Após a triagem dos títulos e resumos das citações identificadas, estudos potencialmente relevantes foram baixados na íntegra. Utilizou-se conjunto de critérios de inclusão prédefinidos para selecionar os estudos referentes às ações de prevenção da Chikungunya.

Resultados: Dos 376 artigos, 177 eram duplicados. Pela leitura de título e resumo, excluíram-se 145. Selecionaram-se 19 artigos. A informação em saúde confere o seu domínio na literatura da vigilância entomológica e epidemiológica, aponta desafios para educação permanente dos profissionais da saúde.

Considerações finais: As ações para prevenção e controle vetorial - em especial às de comunicação de riscos - não têm influenciado o comportamento, impulsionando somente mudanças pontuais, ou seja, atitudes. Percebe-se, entretanto, a tendência em não considerar os saberes e práticas comunitários e populares, bem como a participação ativa e protagonista da população.

Palavras chave: Scoping review, Vírus Chikungunya, Informação em Saúde, Educação em Saúde, Comunicação em Saúde, Prevenção 